${ }^{1}$ Department of Health Sciences and Children's Dentistry, Piracicaba Dental School, University of Campinas, São Paulo, Brazil. Av. Limeira, 901 - P.O. BOX 52. Piracicaba, SP, 13414-903, Brazil.

${ }^{2}$ Faculty of Dentistry of Uberlândia, Federal University of Uberlândia, Brazil

Av. Pará, 1720, Block 4L, Annex B, Room 34 - Campus Umuarama, Uberlândia, MG, 38400-902.

${ }^{3}$ Department of Preventive Medicine, Federal University of São Paulo, Brazil. R. Sena Madureira 1500 - Vila Clementino, São Paulo, SP, 04021-001.

*Corresponding author: Inara Pereira da Cunha E-mail: inara-pereira@hotmail.com Department of Community Dentistry, Piracicaba Dental School, State University of Campinas, São Paulo, Brazil. Av. Limeira, 901 - P.O. BOX 52. Piracicaba, SP, 13414-903, Brazil.

Received: October 13, 2020

Accepted: January14, 2021

\section{Caries experience in children under 5 years old in the Xingu indigenous park in Brazil}

\author{
Alana Cristina Guisilini ${ }^{1}$ (iD, Jaqueline Vilela \\ Bulgareli $^{2}$ iD, Luciane Miranda Guerra ${ }^{1}$ (iD, Antonio \\ Carlos Pereira ${ }^{1}$ (iD), Inara Pereira da Cunha1,* (iD, \\ Pablo Natanael Lemos ${ }^{3}$ (iD, Rosana de Fátima \\ Possobon $^{1}$ iD, Karine Laura Cortellazzi ${ }^{1}$ iD
}

Aim: The present study sought to investigate dental caries experience and its association with sociodemographic, postnatal and breastfeeding variables in children in the agerange from 6 to 71 months of age, in the Xingu Indigenous Park, Mato Grosso, Brazil. Methods: This was an analytical cross-sectional study that used secondary data pertaining to 402 indigenous children of the Low, Middle and Eastern Xingu regions, who participated in the Oral Health Epidemiological Survey in 2013. The dependent variable was dental caries, dichotomized by the median (dmf-t $\leq 1$ and dmf-t>1). The data of independent variables were obtained by means of instruments of the Local Health Information System of the Xingu Indigenous Special Sanitary District (DSEI). Raw analyses were performed to test the association of the independent variables with the dependent variable. The variables were tested in the multiple logistic regression model. Results: The mean value of the dmf-t index was 2.60 and the prevalence of affected children was $51 \%$. In the multiple analysis, only children older than 36 months (OR: 6.64; CI95\%: 4.11 to 10.73) and those that were breastfed for a longer period of time (OR: 1.88; Cl95\%: 1.16 to 3.02) showed significant association with the dmf- $\mathrm{t}>1$ index. Conclusion: Childhood dental caries among indigenous children was associated with age and breastfeeding prolonged for over 26 months, therefore, pointing out the need to offer dental follow-up care at earlier ages.

Keywords: Indians, South American. Dental caries. Breast feeding. Oral health. 


\section{Introduction}

In Brazil, there are approximately 820 thousand indigenous children, who represent almost a third of the total number of Brazilian children ${ }^{1}$, and they are the ones who suffer most with health problems, when compared with non-indigenous children².

As far as oral health is concerned, an unequal distribution of caries disease among children is suspected. The data of the last national oral health survey, known as "SB Brasil 2010," revealed that 5-year-old indigenous children have double the number of cases of dental caries when compared with non-indigenous children in the same age group ${ }^{3}$. This warning has instigated the need for investigations into the area, and it would be interesting to find out about the trajectory of the disease and its early onset, which occurs before children reach the age of 71 months of life $e^{4}$.

Early childhood caries causes pain, difficulties with eating, speaking, sleeping, and socializing. It may compromise children's development and growth and increase the probability of developing disease in their permanent dentition ${ }^{5}$.

This disease develops as a result of the interaction of multiple individual, social and environmental components ${ }^{6}$, such as sex, age, dietary habits, social conditions, and access to oral hygiene instructions ${ }^{7-9}$. Moreover, the causal relations between the time of breastfeeding and caries disease, especially among younger children, must be emphasized ${ }^{10-12}$.

Reports in the literature have indicated that the concentration of lactose in human milk has the capacity to reduce the $\mathrm{pH}$ of dental plaque, thereby contributing to the establishment of caries, particularly when plaque is not removed from the tooth surface by means of correct brushing ${ }^{13}$. Indigenous women of some Brazilian ethnicities are known to have the habit of offering breastfeeding on free demand and for an indefinite period of time ${ }^{14}$, and this is a behavior that must be checked in the indigenous communities, in view of the occurrence of oral health problems, such as dental caries ${ }^{15}$.

The prevalence of dental caries has remained high among the people of the Xingu Indigenous Park (PIX) over the last few years ${ }^{16}$, and the oral health conditions of indigenous children under the age of 5 years, together with the factors associated with them, have hardly been investigated.

Therefore, the aim of the present study was to find out about dental caries experience among children of PIX, under the age of 5 years, and test the hypothesis that caries would be associated with the sociodemographic conditions, post natal and breastfeeding variables. This information could contribute to subsidize strategies for the prevention and control of caries disease among the indigenous children.

\section{Material and Methods}

\section{Ethical aspects}

The project was summited to and approved by the Research Ethics Committee (CEP) of the Piracicaba Dental School of the State University of Campinas (FOP/UNICAMP), Report Number 135/2014, and by the National Commission of Ethics in Research (CONEP), report number 1.018.666/2015. 


\section{Study population}

The Xingu Indigenous Park (PIX) was created by a Federal Government Act in 1961, and is regulated by Decree No. 51.084. Localized in the northeast of the state of Mato Grosso, Brazil, it covers a total area of 2,825,470 hectares ${ }^{17}$. According to Local Health Information System (SLIS) records dated 2013, relative the Xingu Indigenous Special Sanitary District (DSEI Xingu), the PIX is inhabited by 16 indigenous ethnicities, totaling 5,859 inhabitants, distributed among 78 villages that have no fluoridated water.

The PIX is divided into 4 regions that coincide with the following 4 basic poles of health reference: "Polo Base Leonardo Villas Bôas", in the High Xingu region, "Polo Base Diauarum", in the Low Xingu, "Polo Base Pavuru", in the Middle Xingu and "Polo Base Wawi", in the East Xingu regions. Structured with Primary Health Units, these basic poles are served by the activities operated by Multidisciplinary Indigenous Health Teams ["Equipes Multidisciplinares de Saúde Indígena (EMSI)"] with the first reference being the Indigenous Health Agents ["Agentes Indígenas de Saúde (AIS)" and Sanitary Indigenous Health Agents ["Agentes Sanitários Indígenas de Saúde (AISAN)] who work in the villages ${ }^{17}$.

The major portion of the PIX population consists of youngsters, of whom $38.2 \%$ under the age of 15 years; and approximately $5 \%$ are persons over the age of 60 years. As regards proportion between sexes/ethnicity in the territory, a higher number of women (51\%) is observed, and predominance of the Kaiabi ethnicity, of which $43 \%$ of the local population is composed ${ }^{18}$.

\section{Eligibility Criteria}

The survey involved 44 villages in the Low, Middle and East Xingu regions, between the months of April 2012 and April 2013. In the present study, the dmf-t data considered were those of all the children between the ages of 6 and 72 months, who participated in the epidemiological survey. Of the total of 431 existent children under five years of age, 29 (7.7\%) did not participate in the inquiry because they refused or were absent during the period when the exams were performed.

\section{Calibration of examiners}

The examiners were calibrated in accordance with the standards adopted in epidemiological surveys, which consisted of the following steps: a) training in the theoretical framework of the variables used; b)acceptance of the criteria adopted for defining each observation of the exam and its respective codes; c) application of the criteria in real situations; that is, the calibration itself; and e) calculation of intra- and inter-examiner errors, based on the coefficient. The pondered Kappa coefficient for each examiner considered the minimum acceptable limit to be the value 0.65. The Kappa inter-examiner value obtained was 0.90 . The data were noted on paper forms by 3 Indigenous Oral Health Agents, who acted as note-takers.

\section{Study variables and instruments}

In the survey, clinical oral exams were performed to identify decayed, missing and/or filled primary teeth, in order to calculate the dmf-t index. The sociodemographic, post-natal and breastfeeding data were obtained from the Local Health Information System (SLIS) 
and DSEI Xingu, instruments of records dated 2013. The sociodemographic (basic pole, sex, age, Village population size and presence or absence of Indigenous Health Agent or Indigenous Sanitation Agent) were obtained from the demographic census of the villages of DSEI Xingu ${ }^{17}$. The post-natal data (type of delivery and birth weight) were obtain from the birth spreadsheet records, and data about time of breastfeeding were localized on the daily follow-up map of children under the age of five years. This instrument is used by the Indigenous Health Agents and nurses for filling out the breastfeeding data that are inserted into the Local Health Information System of DSEI Xingu.

\section{Statistical Analysis}

The sample size of 402 participants provided a test power of $90 \%(\beta=0.10)$ with a significance level of $5 \%(\alpha=0.05)$ for the effect size found in the study (Odds Ratio of 2.0 and $30 \%$ of response in the unexposed group).

The time of breastfeeding was calculated by measuring the time interval from the child's birth up to the time when the inquiry was conducted. Therefore, if the child were 24 months old on the date of the exam and was still breastfeeding, this was the total period of breastfeeding recorded. Therefore, the time of exclusive breastfeeding was not considered, instead, the time of breastfeeding either associated with or without complementary feeding was considered.

The data collected were tabulated in a Microsoft Excel® 2010. The variable dental caries was described by stratifying the data into age groups and presented as absolute and relative frequency distributions, mean dmf-t values, standard deviations, and dental caries prevalence. The dental caries index (dmf-t) was considered the dependent variable, dichotomized by the median of $\mathrm{dmft}$ (value=1) into: dmf-t $\leq 1$ and $\mathrm{dmf}-\mathrm{t}>1$ ). The independent variables, child's age and time of breastfeeding were also dichotomized by the median into $\leq 36$ months and $>36$ months and $\leq 26$ months and $>26$ months, respectively. The other variables were grouped in the following manner: presence of Indigenous (AIS) or Sanitary (AISAN) Health Agent in the village: yes or no; basic pole: Diauarum, Pavuru or Wawi; child's sex: female or male; type of delivery: vaginal or cesarean; birth weight: $<2500 \mathrm{~g}$ or $\geq 2500 \mathrm{~g}$; village population size: small, for villages with population smaller than or equal to 50 inhabitants, medium for villages with population between 50 and 250 inhabitants or large, for villages with population larger than 250 inhabitants.

Association of the independent variables with the dependent variable was tested by raw analysis. The variables with $p<0.20$ in the simple analysis were tested in the multiple logistic regression model by using the stepwise procedure. The Odds Ratio (OR) and respective confidence intervals of $95 \%$ (IC) were estimated for the variables that remained in the final model, at the level of significance of $5 \%$. All statistical tests were performed with SAS program 9.3 (Institute Inc., Cary, NC, USA). A residual analysis was performed and applied the Hosmer and Lemeshow Goodness-of-Fit test that showed a good fit of the model $(p=0.6880)$.

\section{Results}

Of the total number of 402 indigenous children studied, aged between 6 and 71 months, $208(51.70 \%)$ were of the female sex. Over half of the children had had previous caries 
experience, with a mean dmf-t index of 2.60; with children in the group between 60 and 71 months old showing the highest dmf-t index (5.81). The highest caries prevalence was found in children from 48 to 59 months old, with $87.87 \%$ of these children being affected by the disease (Table 1).

Table 1. Distribution, mean value of dmf-t index, standard deviation and prevalence of dental caries among indigenous children, according to age-group.

\begin{tabular}{lccc}
\hline Age group Months & $\mathbf{n}(\%)$ & Mean dmf-t (sd) & Caries Prevalence (\%) \\
\hline $6-17$ & $73(18.15)$ & $0.10(0.54)$ & 5.47 \\
\hline $18-36$ & $128(31.84)$ & $1.43(2.32)$ & 36.71 \\
\hline $37-47$ & $77(19.15)$ & $3.18(3.89)$ & 59.74 \\
\hline $48-59$ & $66(16.41)$ & $4.36(3.35)$ & 87.87 \\
\hline $60-71$ & $58(14.42)$ & $5.81(4.23)$ & 86.20 \\
\hline Total & $402(100)$ & $2.60(3.60)$ & 50.99 \\
\hline
\end{tabular}

Note: $\mathrm{n}=$ number of children examined; $\mathrm{dmf}$ - $\mathrm{t}=$ Caries Index for primary teeth; $\mathrm{sd}=$ =standard deviation

Table 2 shows that there were a higher number of participants in the low region of Xingu Indigenous Park (54.98\%), with predominance of the female sex (51.74\%), and children delivered by vaginal birth (92.54\%). The majority of the children had a birth weight equal to or higher than $2500 \mathrm{~g}(88.81 \%)$, and a time of breast feeding shorter than or equal to 26 months (51.00\%). The majorities of the villages were of medium size (53.48\%), and had the presence of an AIS/AISAN (97.51\%).

In the multiple logistic regression, the children over the age of 36 months had 6.64 times more chance of having a caries index higher than 1 than those of an age lower than or equal to 36 months. Furthermore, children who were breastfeed for longer than 26 months $(\mathrm{OR}=1.88)$ had more chance of having a dmf-t index higher than 1 (Table 2).

\section{Discussion}

The growing interest in childhood dental caries has been emphasized in the latest national researches that have investigated the indigenous populations ${ }^{19-21}$. Among the children under 71 months old, in the present research over half of them were found to have experienced caries, which showed association with age and time of breastfeeding.

In indigenous children, the association of dental caries experience with the increase in their age is plausible since a previous study found that among the indigenous women of Kaiowa ethnicity in Mato Grosso do Sul, the mean dmf-t tripled with the increase in children's age, especially between 12 and 24 months of life ${ }^{15}$.

While among the indigenous Baniwa of Alto Rio Negro, the mean dmf-t index more than doubled between the ages of 36 and 48 months $^{19}$; and among the indigenous Kotiria in Alto Rio Negro, the mean dmf-t index was 4.72 among children from 1 to 5 years of age $^{20}$. When all the ethnicities studied in the Xingu Indigenous Park were considered, an increase was also observed in the mean dmf-t index in the age group from 0 to 36 months and from 48 to 60 months old ${ }^{21}$. 


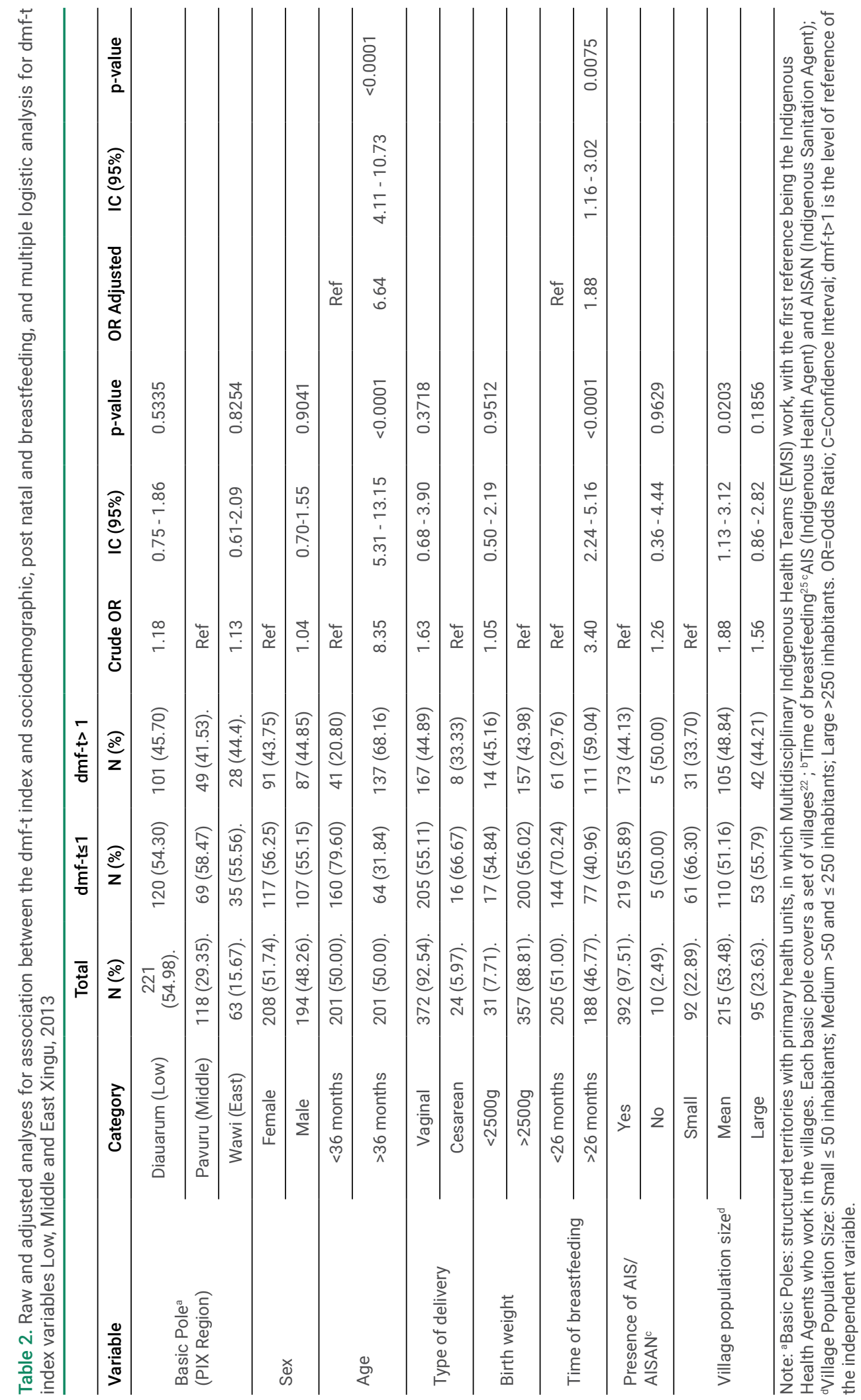


The justification for the association between these two variables is based on the cumulative nature of the caries index over the course of years ${ }^{22}$ and on the relations between the development of caries lesions and chronology of tooth eruption. This is because the tooth surfaces are affected as a result of the time during which they remain exposed to the risk factors present in the oral cavity ${ }^{23}$. This is a natural fact that has been observed, however, the factors that cause concern are the magnitude of differences in the prevalence rates and levels of severity of the disease among the age groups studied.

When the epidemiological findings were compared with the results of the last national oral health survey in Brazil, the mean dmf-t of children from 60 to 71 months of age in this study was observed to be higher than the national mean value of non-indigenous children (2.43 teeth with caries experience) ${ }^{24}$. Similarly, the prevalence of children with caries was also higher than the Brazilian mean (53.4\%) for the age group from 60 to 71 months, demonstrating the possibility of inequalities existent between indigenous and non-indigenous populations, and revealing the need to implement strategies of preventive actions directed towards this segment of the population.

Indeed, progressive reduction in dental caries had been expected in the Low, Middle and East Xingu regions, as a result of a series of public and social actions in the region, especially the increase in financial investments, from the time the Xingu Indigenous Special Sanitary District (DSEI) was created in 1999. This strategy, together with the training and presence of the Indigenous Health Agents (AIS), and Indigenous Sanitation Agents (AISAN) has improved and extended the structure of the health services ${ }^{25}$. In spite of the importance of these professionals in the villages, no association of this variable with the reduction in prevalence of childhood caries experience was found in the present study. The competence of these professionals is not confined exclusively to oral health actions, as they need to provide general guidance about health care during breastfeeding and healthy eating habits of small children. Moreover, public health surveillance forms part of public health practice and involves actions of health promotion developed by these professionals ${ }^{25}$. Therefore, we suggest that reflections about educational methods in oral health should be shared with the technical professionals that work in the villages.

The high dental caries indexes in both PIX and other indigenous populations are influenced by various determinants such as living conditions ${ }^{7-9}$. The sociodemographic conditions were investigated from this aspect relative to the outcome. The variable village population size was found to be associated with the dmf-t index exceeding 1, however, it did not remain in the adjusted multiple logistic analysis model. Village population size is a factor that depends on the sociocultural characteristics of each ethnicity, since some ethnic groups form large communities, and others live in small family nuclei, exhibiting extensive ethnic diversity (16 ethnicities). Therefore, association between village population size and dental caries could be related to the different factors, e.g., economic, sociocultural, localization, infrastructure, type of access and use of health services, and the different ethnicities of residents in the park. Alves Filho et al. ${ }^{24}$ (2013) and Arantes and Frazão 
$(2016)^{26}$ have previously demonstrated the association of these variables with the occurrence of dental caries in other indigenous populations.

The authors point out that that the World Health Organization recommends the practice of breastfeeding up to the age of two years; moreover, it should be complemented with other foods as from six month of age, as this is fundamental for healthy development $^{18}$. In the present study, almost half of the children (46.7\%) of the villages in the Low, Middle and East Xingu regions were breastfed for extended periods of over 26 months. This clearly benefitted both mothers and children, as has been described in the literature ${ }^{12}$. Nevertheless, although this practice apparently was advantageous to indigenous community, the children breastfed for a longer period of time, and older children were observed to be those most affected by caries experience.

Each ethnic group has its own peculiarities that influence the practice of breastfeeding ${ }^{14,19}$. Among the indigenous of Xakriabá ethnicity, interior of the state of Minas Gerais, the median time of breastfeeding was from six to twelve months, with high prevalence of early weaning, in which $49 \%$ of the children no longer received mother's milk before they completed one year of life. The short duration of breastfeeding was explained by the introduction of water and teas, according to guidance provided by the village elders and contact with non-indigenous people ${ }^{14}$. Whereas in the Xingu Indigenous Park, indigenous children culturally tended to be breastfed from the first year through to the third year of life, irrespective of the introduction of solid foods ${ }^{27,28}$.

The relationship of association between breastfeeding for longer than 24 months and being affected by dental caries has previously been shown in the literature. Chaffee et al. ${ }^{10}$ (2014) and Tham et al. ${ }^{11}$ (2015) affirmed that dental caries was associated with the time of breastfeeding when the child was offered the breast frequently during the day and night. This led to reduced saliva production and facilitated milk stagnating in the mouth, so that occurrence of the two factors with absence of oral hygiene led to caries.

There is a hypothesis that mother's milk has factors that provide protection against dental caries, such as the presence of casein protein and imunoglobulin A ( $\lg A)$, which inhibit the growth and adhesion of cariogenic bacteria on tooth surfaces, particularly Streptococcus mutans. In breastfed children, another complementary mechanism of initial protection against caries disease is the healthy oral microbiome established by exposure to mother's milk and her skin ${ }^{29}$. Neves et al. (2016) ${ }^{30}$ evaluated the acidogenicity of human milk in children with and without caries lesions and revealed that breastfeeding did not cause a reduction in the $\mathrm{pH}$ of dental biofilm, irrespective of the presence or absence of caries lesions.

Therefore, breastfeeding in early childhood may well protect against dental caries, however, the time of breastfeeding and behavioral components (such as cleaning the teeth and supporting structures) may significantly contribute to the increase in dental caries in children breastfed after 12 months of age ${ }^{11}$. Furthermore, the risk of dental caries increases, depending on the carbohydrate content, acidity and frequency of consumption of these types of foods. When associated with poor oral hygiene, these foods become essential factors for development of the disease, making them factors that could be confounded with the time of breastfeeding ${ }^{11}$. Therefore, it was perceived 
that breastfeeding of itself was not the sole factor contributing to caries disease progression, but that other factors, including its practice in conjunction with a cariogenic diet, were involved.

The above-mentioned conditions are exacerbated by the absence of behaviors relative to oral health care, especially as the children get older, new primary teeth erupt, and they are exposed to certain groups of foods, possibly leading to changes in the microbiome and increasing the risk of developing dental caries.

The present study had some important limitations related to the methodological approach, with respect to controlling potential confounding factors, such as cariogenic diet and oral hygiene that were not studied, and could have had a negative impact on the children's oral health. Another limitation was the cross-sectional study design that did not allow causal inferences to be made, therefore, only associations between the independent variables and the dependent variable - dental caries (dmf-t index) could be demonstrated.

However, the study was conducted with the intention of identifying caries experience in indigenous children under the age of five years, and possible factors related to this outcome, in order to produce new knowledge, based on strategies with actions to improve the health of this segment of the population The findings on dental caries in indigenous children of PIX demonstrated the need for actions promoting oral health, preventing oral diseases and providing dental care for children in the age group studied, within the Oral Health program of DSEI Xingu. As a coping strategy, we suggest that the oral health teams become more involved in periodic actions of prenatal care and puericulture. Continual guidance and encouragement of exclusive breastfeeding up to 6 months, and complementary feeding without restrictions of time or frequency, up to at least 2 years of age, as recommended by the World Health Organization, must be provided, considering the benefits of breastfeeding to both mother and child ${ }^{11,12}$. Moreover, oral hygiene instructions and healthy dietary practices must be reinforced, considering the sociocultural and local characteristics of the community.

Lastly, we suggest that educational actions implemented should involve members of the family, such as caregivers (sibling, uncles and aunts, grandparents) and that members of the community (midwives, shamans, teachers) should participate in demonstrating the traditional care practices. Since the villages have no fluoridated water, we suggest periodical distribution of oral hygiene products, extension of preventive actions of topical fluoride application, including children under 5 years of age. The IAS/AISAN in the villages could also develop periodical actions of guidance on mother and child self care, which must be guaranteed by DSEI Xingu, with a view to improving the oral health conditions of this group.

This study revealed that dental caries experience in indigenous children in the PIX, between the ages of 48 and 71 months, and of those older than 36 months was associated with breastfeeding for a period of longer than one year. Therefore, implementing preventive measures and oral health care for indigenous children under five years of age, and providing the mothers with guidance about oral care to be performed during the breastfeeding period are indispensable actions for diminishing the incidence of caries in this segment of the population. 


\section{References}

1. Ministry of Planning, Budget and Management of Brazil. Brazilian Institute of Geography and Statistics IBGE. 2010 [Population Census: General Characteristics of Indigenous People - results of the universe]. Rio de Janeiro: IBGE; 2012 [cited 2019 Jun 27]. Available from:

http://www.ipea.gov.br/redeipea/images/pdfs/base_de_informacoess_por_setor_censitario_universo_ censo_2010.pdf. Portuguese.

2. United Nations Children's Fund (UNICEF). [30 years of the Convention on the Rights of the Child: advances and challenges for girls and boys in Brazill. São Paulo: UNICEF; 2019 [cited 2020 Jan 15]. Available from:

https://www.unicef.org/brazil/relatorios/30-anos-da-convencao-sobre-os-direitos-da-crianca. Portuguese.

3. Miranda KCO, Souza TAC, Leal SC. Caries prevalence among Brazilian indigenous population of urban areas based on the 2010 National Oral Health Survey. Cienc Saude Colet. 2018 Apr;23(4):1313-22. doi: 10.1590/1413-81232018234.18082016.

4. Drury TF, Horowitz AM, Ismail Al, Msertens MP, Rozier RG, Selwitz RH. Diagnosing and reporting early childhood caries for research purposes. J Public Health Dent. 1999;59(3):192-7. doi: 10.1111/ j.1752-7325.1999.tb03268.x.

5. Anil S, Anand PS. Early childhood caries: prevalence, risk factors, and prevention. Front Pediatr. 2017 Jul;5:157. doi: 10.3389/fped.2017.00157.

6. Peltzer K, Mongkolchati A. Severe early childhood caries and social determinants in three-yearold children from Northern Thailand: a birth cohort study. BMC Oral Health. 2015 Sep;15:108. doi: 10.1186/s12903-015-0093-8.

7. Arantes R, Santos RV, Frazão P. Between-group differences in dental caries in Xavante Indians from Central Brazil. Rev Bras Epidemiol. 2010;13(2):223-36. Portuguese. doi: 10.1590/S1415790X2010000200005.

8. Sampaio FC, Freitas CHSM, Cabral MBF, Machado ATAB. Dental caries and treatment needs among indigenous people of the Potiguara Indian reservation in Brazil. Rev Panam Salud Publica. 2010 Apr;27(4):246-51. doi: 10.1590/s1020-49892010000400002.

9. Alves Filho P, Santos RV, Vettore MV. [Factors associated with dental caries and periodontal disease in indigenous people of Latin America: systematic review]. Rev Panam Salud Publica. 2014;35(1):6777. Portuguese.

10. Chaffee BW, Feldens CA, Vítolo MR. Association of Long-Duration Breastfeeding and Dental Caries Estimated with Marginal Structural Models. Ann Epidemiol. 2014 Jun;24(6):448-54. doi: 10.1016/j. annepidem.2014.01.013.

11. Tham R, Bowatte G, Dharmage SC, Tan DJ, Lau MXZ, Dai X, et al. Breastfeeding and the risk of dental caries: a systematic review and meta-analysis. Acta Paediatr. 2015 Dec;104(467):62-84. doi: 10.1111/apa.13118.

12. Victora CG, Barros AJD, França GVA, Bahl R, Rollins NC, Horton S, et al. Breastfeeding in the 21st century: epidemiology, mechanisms, and lifelong effect. Lancet. 2016 Jan;387(10017):475-90. doi: 10.1016/S0140-6736(15)01024-7.

13. Peres KG, Nascimento GG, Peres MA, Mittinty MN, Demarco FF, Santos IS, et al. Impact of prolonged breastfeeding on dental caries: a population-based birth cohort study. Pediatrics. 2017 Jul;140(1):e20162943. doi: 10.1542/peds.2016-2943.

14. Sírio MAO, Freitas SN, Figueiredo AM, Gouvêa GDR, Pena JL, Machado-Coelho GLL. [Duration of breastfeeding among the indigenous Xakriabá people living in the Minas Gerais state, Southeast Brazil]. Rev Nutr. 2015;28(3):241-52. Portuguese. doi: 10.1590/1415-52732015000300002. 
15. Parizotto SPCOL. [Prevalence of dental caries in primary dentition of children from the Kaiowá Guarani indigenous community of Mato Grosso do Sul and association with risk factors] [thesis]. São Paulo: Faculty of Dentistry, University of São Paulo; 2004.

16. Lemos PN, Rodrigues DA, Frazão P, Coelho CC, Campos JNS, Narvai PC. Dental caries in peoples of Xingu Indigenous Park, Brazil, 2007 and 2013. Epidemiol Serv Saude. 2018 Feb;27(1):e20171725. doi: 10.5123/S1679-49742018000100005.

17. DSEI XINGU. [Demographic Census and Forms of the Local Health Information System of the Xingu Indigenous Sanitary District]. Canarana, Mato Grosso; 2013. Portuguese.

18. Lemos PN, Rodrigues DA, Frazão P, Hirooka LB, Guisilini AC, Narvai PC. [Oral health care in the Xingu Indigenous Park, Brazil, from 2004 to 2013: an analysis based on evaluation indicators]. Cad Saude Publica 2018;34(4), e00079317. Portuguese. doi: 10.1590/0102-311×00079317.

19. Carneiro MCG, Santos RV, Garnelo L, Rebelo MAB, Coimbra Jr CEA. [Dental caries and need for dental care among the Baniwa Indians, Rio Negro, Amazonas]. Cienc Saude Colet. 2008;13(6):198592. Portuguese. doi: 10.1590/s1413-81232008000600034.

20. Côrtes G. [Dental caries and associated factors in indigenous Kotiria do Alto Rio Uaupés, AM, Brazil] [dissertation]. Manaus: Federal University of Amazonas; 2013. Portuguese.

21. Pacagnella, RC. [Epidemiological Profile of Oral Health of the Population of the Xingu Indigenous Park, between 2001 and 2006] [dissertation]. Ribeirão Preto: Ribeirão Preto School of Medicine, University of São Paulo; 2007

22. Ministry of Health of Brazil. Health Care Secretariat. Health Surveillance Secretariat. [SB BRAZIL 2010: national research on oral health: main results]. Brasilia: Ministry of Health of Brazil; 2012 [cited 2020 Sep 23]. Available from:

http://bvsms.saude.gov.br/bvs/publicacoes/pesquisa_nacional_saude_bucal.pdf. Portuguese.

23. Barros SG, Alves AC, Pugliese LS, Reis SR. [Contribution to the study of dental caries in 0-30-monthold infants]. Pesqui Odontol Bras. 2001 Jul-Sep;15(3):215-22. Portuguese. doi: 10.1590/s151774912001000300007.

24. Alves Filho P, Santos RV, Vettore MV. Social and environmental inequities in dental caries among indigenous population in Brazil: evidence from 2000 to 2007. Rev Bras Epidemiol. 2013;16(3):692704. doi: 10.1590/S1415-790X2013000300013.

25. Ministry of Health of Brazil. Secretariat for Management of Work and Education in Health. Department of Management of Education in Health. [Qualification Program for Indigenous Health Agents (AIS) and Indigenous Sanitation Agents (AISAN)]. Brasília: Ministry of Health; 2016. Portuguese.

26. Arantes R; Frazão P. Income as a Protective Factor for Dental Caries among Indigenous People from Central Brazil. J Health Care Poor Underserved. 2016;27(1A):81-9. doi: 10.1353/hpu.2016.0043.

27. Mattos A, Morais MB, Rodrigues DA, Baruzzi RG. Nutritional status and dietary habits of Indian children from Alto Xingu (Central Brazil) according to age. J Am Coll Nutr. 1999 Feb;18(1):88-94. doi: 10.1080/07315724.1999.10718832.

28. Fagundes-Neto U, Baruzzi RG, Wehba J, Silvestrini WS, Morais MB, Cainelli M. Observations of the Alto Xingu Indians (Central Brazil) with special reference to nutritional evaluation in children. Am J Clin Nutr. 1981 Oct;34(10):2229-35. doi: 10.1093/ajcn/34.10.2229.

29. Holgerson PL, Vestman NR, Claesson R, Öhman C, Domellöf M, Tanner ACR et al. Oral Microbial Profile Discriminates Breastfed from Formula-Fed Infants. J Pediatr Gastroenterol Nutr. 2013 Feb;56(2):127-36. doi: 10.1097/MPG.0b013e31826f2bc6.

30. Neves PA, Ribeiro CC, Tenuta LM, Leitão TJ, Monteiro-Neto V, Nunes AM, et al. Breastfeeding, dental biofilm acidogenicity, and early childhood caries. Caries Res. 2016;50(3):319-24. doi: 10.1159/000445910. 